\title{
El giro posmoderno en la archivología
}

Virginia Castro*

\section{Introducción}

Si bien al día de la fecha el debate modernidad-posmodernidad que tomó lugar en la década de 1980, puede impresionarnos como algo ya lejano y por demás sancionado, la oposición modernidad-posmodernidad en la teoría social y modernismo-antimodernismo en las artes, fue uno de los espacios de mayor beligerancia de la vida intelectual en Occidente, siendo mucho más que la existencia (o no) de un estilo artístico o la corrección de una línea teórica lo que estuvo entonces en juego., ${ }^{12}$ En efecto, poco antes de la caída del muro de Berlín $-\mathrm{y}$, con mayor encono, inmediatamente después de la extinción del llamado "socialismo real"-, cientistas sociales, filósofos, artistas y teóricos del arte debatieron sobre nociones tales como el sujeto de la historia, la aspiración a los saberes totalizadores, las ideas de fundamento y telos, la posibilidad o no de una teoría unitaria, los conceptos de ciencia, saber y verdad.

La implosión de la ex Unión Soviética y la concomitante desaparición del horizonte de la revolución en un mundo que por primera vez se veía como fatalmente capitalista, también fue motivo de largas disquisiciones (a favor y en contra) de la efectiva existencia del llamado "fin de los grandes relatos" (en lo específico: del marxismo) y/ o el llamado por otros "fin de la Historia". También se enunciaron otros "fines": el fin de la filosofía, el fin de la novela ( $y$ de la literatura), el fin de las artes plásticas, el fin de la política... Mientras unos celebraron la condición posmoderna, otros la impugnaron in toto, homologándola a la apoliticidad, la pérdida de sentido, el relativismo cínico, la voluntad deshistorizadora, el anti-humanismo. Pero dentro del conjunto de aquellos que admitieron que dicha condición se había transformado en un dato ineludible, también es posible discernir una entonación crítica, que vio en dicha coyuntura una posibilidad de revisitar valga la redundancia: críticamente- el proyecto (o bien fallido, o bien inconcluso) de la Modernidad.

No es fácil zanjar en pocas líneas un balance de aquel debate, si se quiere todavía abierto. Pero quizás, para poder pasar al punto siguiente, cabría decir que todos los actores reconocían la necesidad de repensar la modernidad, ya fuera en términos de la crisis

\section{* $\quad \mathrm{CeD} \ln \mathrm{Cl} /$ UNSAM}

1 Andreas Huyssen, "Guía del posmodernismo", Punto de Vista, n²9, 1987, Separata.

2 Dedico este trabajo a mi colega Eugenia Sik, con quien tengo el gusto de trabajar en el Área de Archivos y Colecciones Particulares del CeDInCl desde febrero de 2015 de un proyecto inacabado (Habermas), ${ }^{3}$ ya fuera celebratoriamente como fin (Fukuyama), así como la necesidad de sopesar el desafío de la posmodernidad, fuera que se la asumiera como una "condición" ineludible signada por la "incredulidad frente a las metanarrativas" (Lyotard), 5 o bien como "lógica cultural del capitalismo tardío" (Jameson). 6

De todos los nombrados, fue indudablemente Jameson el que acertó en entender la posmodernidad como un nuevo momento del capitalismo multinacional en la célebre conferencia pronunciada en 1982 en el Whitney Museum of Contemporary Arts, publicada como artículo dos años más tarde y núcleo de su futuro libro intitulado Posmodernism, Or, the Cultural Logic of Late Capitalism. Y también acertó en señalar que debía apuntarse a una comprensión totalizadora del nuevo capitalismo ilimitado, adecuada a la escala global de sus conexiones y disyunciones, evitando la tentación del moralismo. En otras palabras: evitando a toda costa una decidida valoración positiva o negativa de lo posmoderno como cultura. En este sentido, otro de sus aciertos fue proceder a un análisis de todas las artes en la coyuntura de este nuevo estadio de la historia del modo de producción dominante (si bien, por formación e intereses, sus análisis se centran en la arquitectura, la literatura y el cine posmodernos).

El impacto del llamado "giro posmoderno" alcanzará a la Archivología recién una década y media más tarde, al publicarse un texto si se quiere emblemático: Mal de Archivo: una impresión freudiana (1995), de Jacques Derrida, originado en una conferencia dictada el año anterior.? Pero antes de proceder a su glosa y

3 Jürgen Habermas, "La modernidad: un proyecto inacabado", Ensayos políticos, Península, Barcelona, [1981] 1988, pp. 19-36.

4 Fukuyama, Francis, El fin de la historia y el último hombre, Barcelona, Planeta de Agostini, [1992] 1994

5 Lyotard, Jean-François, La condición posmoderna, Madrid, Ediciones Cátedra, [1979] 2004.

6 Jameson, Fredric, Posmodernism, Or, the Cultural Logic of Late Capitalism, Durham, North Carolina, Duke University Press, 1991.

7 Cabe recordar que escaso tiempo antes Derrida había publicado en Éditions Galilée la versión en libro de otra conferencia, "Espectros de Marx", dictada en dos sesiones -el 22 y 23 de abril de 1993- en la Universidad de California (Riverside). Allí, denuncia el nuevo dogmatismo de aquellos que desde un determinado espacio geopolítico niegan la vigencia del pensamiento de Marx y/o su posible recuperación. Derrida señala que siempre será un error dejar de leer (de discutir) a Marx, habida cuenta de que habitamos una cultura que conserva, de manera visible o no, la profunda marca de esa herencia. Por lo mismo, en su argumentación relee de manera magistral motivos y nociones presentes en el Manifiesto, La ideología alemana, Contribución a la crítica de la economía 
análisis, cabría aclarar tres cosas.

Primero: la preocupación por la noción de "archivo" por parte de Derrida no comienza en 1994, sino que articula directamente con una serie de preocupaciones y desarrollos previos alrededor del estatus de la escritura, la inestabilidad del texto y de la relación texto-productor, la dialéctica presencia-ausencia, los conceptos de différance, trazo, inscripción, origen. Segundo: la archivología ya había comenzado a cuestionar sus propios fundamentos algunos años antes de la aparición de Mal de Archivo en formato libro. Al respecto, cabría mencionar aportes como: "Mind over Matter: Towards a New Theory of Archival Appraisal" (1992) de Terry Cook; "Orders of Value: Probing the Theoretical Terms of Archival Practice" (1991), de Brian Brothman; "The Value of 'Narrativity' in the Appraisal of Historical Documents" (1991), de Richard Brown, y, especialmente, el artículo de Cook "Electronic Records, Paper Minds: The Revolution in Information Management and Archives in the Post-Custodial and Post-Modernist Era" (noviembre de 1994), donde aparece la primera mención al posmodernismo en el ámbito angloparlante por parte de un archivista profesional.

Dicho de otro modo: Derrida no habría sido el primero en repensar la noción de archivo, la acción de archivar, el archivo en tanto institución y el rol de sus gestores y administradores, si recabamos en que estas deliberaciones ya habían comenzado poco antes en el seno mismo de la disciplina archivística. $Y$, en tercer lugar, las prácticas mismas habrían estado acompañando y/ o rebasado toda reflexión al respecto.

No obstante, es justo precisar que el texto Mal de archivo -que fue casi inmediatamente traducido al inglés como "Archive Fever": obsérvese el cambio de lexema - tuvo un efecto considerable en los profesionales de la disciplina, al tratarse de un aporte firmado por el que era entonces considerado el principal pensador posmoderno, tanto en la academia francesa (europea) como en la norteamericana. Y porque en Mal de Archivo la preocupación por la noción de archivo es central, a diferencia de lo que ocurre en otros dos textos derridianos precedentes, donde la noción de archivo también aparece, pero de manera no tan privilegiada: La Carte Postale de Socrate à Freud et au dèla (1980) y "Coup d'envoi" (1990), ensayo introductorio al volumen Reading the Archive. On Texts and Institutions, cuyos editores fueron Janie Vanpée y E. S. Burt, para la colección French Studies de la Universidad de Yale.

política y El 18 Brumario de Luis Bonaparte, para, precisamente, atacar los presupuestos y conclusiones de Francis Fukuyama en El fin de la historia y el último hombre, al mismo tiempo que se coloca en diálogo con, entre otros, Maurice Blanchot, Emmanuel Lévinas, Etienne Balibar Alexandre Kojève y Ernesto Laclau. Todo esto supuso un sorpresivo desaire para algunos de sus colegas de la academia norteamericana, que muy presumiblemente, habían esperado que Derrida asumiera una muy diferente posición.
En una serie de artículos que comenzaron a publicarse ya sobre el filo del cambio de siglo (del siglo XX al siglo XXI), profesionales de la archivística como Terry Cook, Joan M. Schwartz, Tom Nesmith y Heather MacNeil, entre otros, se ocuparon de subsanar la distancia entre las intuiciones alrededor de la mutación que estaría sufriendo el concepto de "archivo" — de cuño más bien especulativo y filosófico— plasmadas por Derrida y el efecto directo que esta mutación habría ocasionado en el orden de las prácticas. Por último, Cook, se encargó de razonar qué cambios en la disciplina podían explicarse según esta renovada noción de "archivo" según Derrida y qué otros tenían su explicación en otros dos factores exógenos: la "revolución informática" y las nuevas demandas que la sociedad civil presenta al archivo en tanto institución, y, por ende, las nuevas demandas y desafíos que se les presentan inevitablemente a los profesionales que trabajan allí.

Hechas estas salvedades, el primer apartado de la presente comunicación versará sobre la reformulación de la noción de "archivo" por parte de Jacques Derrida en Mal de archivo. Inmediatamente después, recuperaremos lo principales aportes de Terry Cook en lo que hace al cambio de paradigma en la disciplina archivística. Por último, en una muy breve coda, deslizaremos algunas consideraciones preliminares sobre un posible estudio de caso: la labor que desde el año 2011 vienen desarrollando los trabajadores del área de "Archivos y Colecciones Particulares" del Centro de Documentación e Investigación de la Cultura de Izquierdas (CeDlnCl).

\section{Mal de archivo: una impresión freudiana}

Me gustaría empezar situando, a la manera de los historiadores, el texto de Jacques Derrida, que, como dije en el apartado anterior, fue inicialmente una conferencia intitulada "El concepto de archivo. Una impresión freudiana", pronunciada el 5 de junio de 1994 en la casa-museo de Freud en Londres, en ocasión del coloquio internacional "Memory: The Question of Archives". Organizado por iniciativa de René Major y Elisabeth Roudinesco, bajo los auspicios de tres instituciones: la Société Internationale d'Histoire de la Psychiatrie et de la Psychoanalyse, el Freud Museum y el Courtauld Institute of Art.

A lo largo de su exposición oral, Derrida hace tres veces referencia al lugar de enunciación: la casa-museo de Freud en la calle Maresfield Gardens de Londres, la morada que ocupó hasta su muerte tras salir de Viena luego de la Anschluss, la anexión al Tercer Reich votada por los austriacos el 12 de marzo de 1938. Y lo hace porque en esa casa se conserva parte del archivo personal de Sigmund Freud y parte de su biblioteca. Entonces: a sus reflexiones se les impone el lugar (se le impone la casa-museo 
como institución-museo, y como institución-archivo). Y, además, se les impone un libro aparecido escaso año antes en traducción francesa, Freud's Moses. Judaism Terminable and Interminable, de Yosef Hayim Yerushalmi, donde éste - a partir del hallazgo de un ejemplar reencuadernado de una Biblia Philippsohn con una extensa dedicatoria de Jakob Freud en la biblioteca personal conservada del padre del psicoanálisis - trata de repensar la caracterización antisemita del psicoanálisis como "ciencia judía" y de reubicar a Sigmund Freud en el seno mismo de lo que él entiende por "judeidad", caracterizada apenas (y nada menos...) que por la apertura al porvenir y el mandato de la memoria (el mandato de no olvidar el pasado).

Como Freud, como Yerushalmi, Derrida es también judío. Pero no es solamente esta pertenencia común a la "judeidad" ni la casa-museo como lugar de enunciación las que explicarían porqué precisamente en esta conferencia al filósofo francés le interesa por primera vez detenerse largamente en el concepto de "archivo", sino un punto de partida quizá algo discutible. Según Derrida, es precisamente el psicoanálisis el que estaría llamado a revolucionar la problemática del archivo, en tanto su discurso versa, ante todo, "sobre el almacenamiento de las 'impresiones' y el cifrado de las inscripciones, pero también sobre la censura y la represión, la supresión y la lectura de los registros". 8 Desde la primera frase, Derrida enuncia, problematizándola, la cuestión que desarrollará a lo largo de su comunicación: “¿Por qué reelaborar hoy día un concepto del archivo? ¿En una sola y misma configuración, a la vez técnica y política y jurídica?" ${ }^{\prime 9}$

Como todo filósofo, Derrida ama las etimologías, por lo que inicialmente se detiene largamente en la palabra arkhé ("archivo", que "nombra a la vez el comienzo y el mandato"), para llegar a una primera noción tradicional de archivo en términos "topo-nomológicos". Según Derrida, el archivo, fue, tradicionalmente, "exterioridad de un lugar, puesta en obra topográfica de una técnica de consignación, constitución de una instancia y de un lugar de autoridad [...] allí donde los hombres y los dioses mandan [...] en ese lugar desde el cual el orden es dado..." 10 Y el arkhefon ("arconte", "archivista"), el "guardián" de dicho lugar de autoridad, de dicho lugar desde donde la ley emana y se imparte.

No obstante, Derrida pasa inmediatamente a desestabilizar estas conceptualizaciones tradicionales, retomando el concepto freudiano de "pulsión de muerte" ("pulsión de agresión, de destrucción, de pérdida"), y destacando que "el archivo es hipomnémico". Sobre esto último: el archivo es para Derrida una suerte de suplemento o representante mnemotécnico, auxiliar o memorándum, todo lo contrario de la memoria espontánea. Como dis-

8 Jacques Derrida, Mal de Archivo: una impresión freudiana, Madrid, Edtorial Trotta, 1997, pp. 1-2.

$9 \quad$ lbíd., p. 1.

$10 \quad$ lbíd., p. 2. positivo monumental, como hypómnema, el archivo tiene lugar precisamente cuando ocurre este desfallecimiento originario y estructural de la memoria en tanto experiencia viva e interior, por lo que una de sus funciones principales deberá ser necesariamente el asegurar la posibilidad de la memorización, de la repetición, de la reproducción, de la re-impresión." Trazando una relación directa harto discutible entre "repetición" y "pulsión de muerte" (que soslaya la cuestión freudiana del trauma), Derrida concluye que, en tanto dispositivo hipomnémico, el archivo se ve amenazado desde su interior mismo por el principio destructor del olvido. En palabras de Derrida: "el archivo trabaja siempre y a priori contra sí mismo".12

A la concepción tradicional de archivo, Derrida termina oponiéndole así una nueva, construida sobre una serie de aparentes aporías: el archivo es conservador e instituyente (al redefinir constantemente lo archivable, "la archivación produce, tanto como registra, el acontecimiento"). ${ }^{13}$ El archivo es tradicional, y, a la vez, revolucionario (la cuestión del archivo es una cuestión del porvenir: "la cuestión de una respuesta, de una promesa y de una responsabilidad para mañana") ${ }^{14} \mathrm{~A}$ la idea de los archivistas como meros guardianes ("arcontes"), Derrida le agrega la idea de que "los archivistas producen archivo", ejemplificando esto último con el accionar de Yerushalmi, quien, a partir del "hallazgo crucial" de la Biblia Philippsohn dedicada por Jakob Freud en la biblioteca personal conservada, no sólo reinscribe a Sigmund Freud en la judeidad, sino que - sobre el final de su libro y en el contexto de un monólogo altamente poético, que nada tiene ya de discurso argumentativo- lo obliga a "confesar" cómo esta identidad judía habría estado permeando partes importantísimas de su teoría psicoanalítica — como el complejo de castración-. Y esto, enfatiza Derrida, sólo es posible para Yerushalmi a partir del hallazgo de la dedicatoria de Jakob Freud en el archivo Freud, hallazgo que pone en evidencia el carácter abierto e inabarcable de todo archivo... En este caso, del Archivo Freud, del cual, a su vez, el texto Freud's Moses. Judaism Terminable and Interminable pasaría inmediatamente a ser parte. Y, además (señala Derrida), Yerushalmi realiza esta reinscripción soslayando de manera deliberada el hecho de que Freud mismo había puesto explícita y sistemáticamente en duda la injerencia de la identidad judía en su quehacer intelectual, por considerarse a sí mismo un judío perfectamente asimilado (más austriaco que judío, más "ciudadano del mundo" que austro-húngaro).

Otra de las cuestiones presentes en Mal de archivo a destacar es la importancia otorgada por Derrida a las entonces muy nuevas tecnologías de archivamiento y comunicación. Entregado a una (por él bautizada como) "ciencia ficción retrospectiva", Derrida

$\begin{array}{ll}11 & \text { Ibíd., p. } 8 . \\ 12 & \text { Ibíd., p. } 8 . \\ 13 & \text { Ibíd., p. } 11 . \\ 14 & \text { Ibíd., p. } 21 .\end{array}$


se pregunta qué habría pasado con el "archivo del psicoanálisis" si Freud hubiera dispuesto del correo electrónico y la posibilidad de brindar teleconferencias al momento de gestionar su ingente correspondencia, de las técnicas contemporáneas de grabación y filmación casera para registrar las sesiones con sus pacientes, de la ciencia informática para refinar sus propias metáforas (en lo específico: la del Wunderblock o "bloc mágico" —o "pizarra mágica" - en tanto modelo técnico de máquina/ herramienta para describir la estructura del aparato psíquico). Si bien, al parecer, lo que más interesa a Derrida es esto último, la pregunta por el impacto de un mundo computarizado sobre el concepto de "archivo" y sus funciones mismas seguramente fue una de las cuestiones que más fuertemente resonaron en determinados lectores de Mal de archivo que eran, además, archivistas profesionales. Sobre esta recepción versará el próximo parágrafo.

\section{Un nuevo paradigma archivístico}

En un artículo que inaugura el primer número de la revista Archival Science intitulado "Archival Science and Postmodernism: New Formulations for Old Concepts" (2001), Terry Cook resume ejemplarmente lo que él denomina "el cambio de paradigma archivístico", producido a partir del impacto del "giro posmoderno" en la disciplina, los variados efectos de la revolución informática y las nuevas demandas de la sociedad civil hacia la instituciones que resguardan archivos. Antes de pasar a la exposición, Cook hace una importante salvedad: no se trata de renunciar a principios de eficacia probada, como son el de proveniencia y de orden original. En adhesión a lo explicado por Thomas Kuhn en La estructura de las revoluciones científicas (1962), Cook señala que no son precisamente las preguntas de investigación las que deberían cambiar -qué es un archivo, qué es un documento de archivo, qué principios rectores orientan la organización de fondos documentales, qué es un archivista- sino sus respectivas respuestas las que deberían ahora complejizarse.

Si pensamos el archivo —entendiéndolo como "institución" y "acervo" - en el cambio de paradigma, Cook cita una tan sucinta como precisa definición de Eric Ketelaar: "archivos de la gente, por la gente, para la gente". En otras palabras: la sociedad civil en la actualidad no aspira solamente a poder consultar sin restricciones los archivos todopoderosos y monolíticos del Estado y sus instituciones centrales, incluidos los archivos de sus aparatos represivos, ni a acceder libremente a los fondos personales de figuras prominentes - reyes, obispos, personajes de la cultura y de la Historia de primera línea, escritores célebres-, destinados prototípicamente a la consulta erudita y/ o reverencial, sino también a disponer de nuevos archivos que consignen documentos relativos a los "eternamente silenciados" (minorías que fueron desde siempre desfavorecidas y/ o marginalizadas): los archivos de "la gente infraordinaria", en la formulación de Philippe Artières. $^{15}$

Se les pide en la actualidad a los archivos que no sólo sean de fácil acceso para el público no especializado, sino que vayan al encuentro de la "gente común", aprovechando para ello las posibilidades del entorno digital. Del archivo tradicional "topo-nomológico" como lo explicaba Derrida a los nuevos "archivos sin paredes", según otra frase feliz de Ketelaar en su breve conferencia homónima pronunciada el 22 de 1996 en la Biblioteca Real de Bruselas, de los archivos del poder y de la ley a los archivos en tanto fuentes de Derecho.

El nuevo paradigma revolucionaría también lo que entendemos por documento de archivo. Si antes se pensaba al documento de archivo como fuente de conocimiento más o menos objetivo y fiable que había (más o menos azarosamente) sobrevivido a la erosión del tiempo, originado en el puro accionar de una institución o una persona determinada, ahora se los considerará un constructo, fruto de intencionalidades, moldeado -en el caso de los documentos de archivo de un fondo personal - tanto por la intención autobiográfica de su productor como por las convenciones y géneros de la interacción social. ${ }^{16} Y$ se buscará reconstruir las voluntades múltiples y cadenas de custodia que hicieron posible su supervivencia, buscando discernir tanto lo que dice como lo que elige callar, y las relaciones de poder que le son subyacentes. Al mismo tiempo, la antigua preocupación por la salvaguardia y almacenamiento físico del documento estaría siendo reemplazada en el entorno digital por una nueva preocupación: la necesidad de la migración permanente de formatos.

Por último, el cambio de paradigma impacta en los archivistas mismos, que han pasado de ser los guardianes pretendidamente neutrales de la evidencia que se encontraría disponible en los archivos, a ser figuras mediadoras y facilitadoras del encuentro que se busca propiciar entre los archivos y la sociedad civil, a ser altamente conscientes de que su propio sistema de valores está indefectiblemente en juego en cada una de sus decisiones y acciones, y de que su subjetividad debe ser no sólo expresamente declarada, sino también celebrada. En un largo artículo publicado en 2005, "Picking Our Text: The Archival Description, Authenticity and the Archivist as Editor", Heather MacNeil homologa de manera desafiante la figura del archivista a la del editor de literatura, en el caso de las ediciones críticas donde el objetivo es "fijar" un texto a partir de un cúmulo de borradores y versiones: los archivistas tendrían en este sentido el poder de autenticar

15 Philippe Artières, "Archivarse", en Actas de las II Jornadas de discusión/ I Congreso Internacional. Los archivos personales: prácticas archivísticas, problemas metodológicos y usos historiográficos, Buenos Aires, CeDInCl, 2018. Disponible en http://cedinci.unsam.edu.ar/pdf/jornadas/ Actas-Archivos-Personales.pdf

16 Philippe Artières, "Arquivar a própria vida", en Estudos Históricos, vol 11, $n^{\circ} 21$, Río de Janeiro, 1998, pp. 9-34. Disponible en http://bibliotecadigital.fgv.br/ojs/index.php/reh/article/view/2061. 
y editar documentos, casi tanto como el productor mismo. En un libro publicado en 2012, Descrição e pesquisa: Reflexões em torno dos arquivos pessoais, Lucia Maria Velloso de Oliveira argumenta que el archivista es una suerte de investigador: el archivista, cuando describe un determinado fondo personal, expresa el fruto de una investigación sobre el mismo. La descripción sería así la "función magna" de los archivistas: la producción de un conocimiento sobre los archivos.

Si bien en años recientes se ha focalizado el debate en el proceso de creación e inscripción de los documentos, en la intencionalidad que subyace a ellos y su carácter de constructo, se ha dedicado poca atención a cómo el documento es elegido y moldeado, privilegiado o marginalizado por las intervenciones de los archivistas. La importancia de la performance de los archivistas permanece incluso hoy opaca, invisibilizada, señalan Terry Cook y Joan M. Schwartz en "Archives, Records and Power: From (Posmodern) Theory to (Archival) Performance" (2002). No obstante, el posmodernismo exige a los archivistas explicitar qué metodologías fueron empleadas, revelar cuáles criterios de evaluación documental fueron utilizados, sobre qué conceptos de valor o significación basaron sus decisiones, qué sistema de valores y creencias se refleja en las decisiones tomadas. En otras palabras: reconocer su propio rol creador en el proceso de gestión documental. El archivista debe aceptar que es tanto un mediador como un intérprete.

Los posmodernos ven más valor en las historias que en las estructuras, en los márgenes que en los centros, en lo diverso y ambiguo que en lo certero y lo universal. Por sobre todas las cosas, afirman que ningún actor es un mero observador, sea éste historiador o archivista, ni neutral ni desinteresado en ninguno de los procesos de la gestión documental, así como tampoco ninguno de los textos que ellos manipulan (incluyendo los documentos de archivo) es una ventana transparente a una realidad pasada.

\section{El área de Archivos y Colecciones Particulares del CeDInCl: esbozo para un estudio de caso}

$\mathrm{Si}$, como afirma Eric Ketelaar, hoy celebramos los "archivos sin paredes" resultantes de la llamada "revolución digital", es de destacar que ya desde el año 2012, por iniciativa de dos trabajadores del Centro de Documentación e Investigación de la Cultura de Izquierdas, se implementó el software de código abierto para la descripción archivística AtoM ("Access to Memory"), siendo el $\mathrm{CeDInCl}$ el primer centro de documentación de la región en utilizar este sistema basado en la carga y visualización en la web de descripciones multinivel bajo las normas ISAD(G), ISAAR (CPF), ISDIAH e ISDF.
A fines de 2015, con el mismo software de código abierto y descarga gratuita, se lanzó el banco de imágenes "IMAGOTECA. La colección de imágenes sociales y políticas del CeDlnCl", repertorio de más de 4000 imágenes indizadas. Al año siguiente, fue inaugurado el portal AméricaLEE, desde el cual es posible acceder a ediciones digitales facsimilares de las principales revistas latinoamericanas de fines del siglo XIX y el siglo XX, que nuestra institución resguarda en formato papel. En 2018, con la tecnología de OMEKA, fue inaugurado un segundo portal: "EXHIBICIONES CEDINCI. Recorridos digitales", precisamente con el ánimo de poner a disposición, en formato digital, todos los documentos de todas las muestras realizadas de manera analógica en la Sala de exhibiciones "Clement Moreau" de nuestra Institución.

Dichos pasajes de lo analógico a lo digital (de los documentos-papel resguardados o exhibidos en el CeDInCl a los documentos digitalizados de acceso libre en la WEB) conllevan un plus por demás obvio. No sólo se democratiza absolutamente el acceso al volver posible la consulta desde cualquier puerto remoto, sino que las descripciones, firmadas por especialistas de diversas disciplinas, que acompañan en todos los casos los ítems que son digitalizados, expanden, al enriquecerlos mediante la contextualización, sus posibles usos por parte de investigadores e interesados. Por último, el proceso de digitalización y puesta en acceso por parte de la institución de determinado documento papel especialmente valioso ( $y$, por lo mismo, objeto de intensa manipulación por parte de los usuarios) tiene como bienvenido efecto colateral volver certera la conservación del mismo a largo plazo.

Desde la apertura democrática en nuestro país, los archivos institucionales de gestión pública se han vuelto crecientemente permeables a las demandas de la sociedad civil. Retomando la cita de Eric Ketelaar, asistimos durante las últimas décadas a la emergencia y consolidación de "los archivos de la gente, por la gente y para la gente". Por lo mismo, a la triple función prototípicamente atribuida a los archivos institucionales — salvaguarda de la memoria, posible fuente para las ciencias sociales, garantía de derechos - se sobreimprimiría una tendencia general a la abolición de las jerarquías. Tendencia que no sólo se refleja en la horizontalidad que actualmente define la relación institución-usuario, sino también en los renovados criterios de valoración documental.

Al respecto, cabe destacar que desde sus inicios allá por el año 1996, el CeDlnCl se interesó por recuperar los acervos de militantes y activistas que no eran necesariamente "primeras figuras" de sus partidos, movimientos u organizaciones de pertenencia, desde la creencia de que los respectivos acervos de estos militantes de base y cuadros medios eran tan importantes (si no más) para la Historia Intelectual como aquéllos pertenecientes a los líderes partidarios. Con la misma lógica, se otorgó idéntica importancia 
al rescate de los fondos personales de editores, traductores, bibliotecarios y libreros que al de aquellos pertenecientes a figuras políticas prominentes, reputadas en tanto exegetas del pensamiento de Karl Marx o Mijaíl Bakunin.

(De hecho, el fondo personal fundante del $\mathrm{CeDlnCl}$ es el de José Paniale, un ignoto militante argentino que participó de la reforma universitaria y del grupo Insurrexit. Y una de las colecciones de fotografía política más consultadas es la de Alfredo Alonso, un militante independiente que sin la menor formación técnica decidió registrar con su cámara semiprofesional las manifestaciones políticas de los años 70 y 80 ).

En 2017, por iniciativa de un colectivo de militantes y activistas radicados en el $\mathrm{CeDInCl}$, se creó el "Programa de memorias feministas y sexo-genéricas", un esfuerzo por fortalecer el estudio y el debate acerca de la relación de los movimientos de mujeres, los feminismos y los activismos sexogenéricos con las izquierdas en todo su arco de expresión.

Si uno de los efectos de llamado "giro posmoderno" en la archivología es la certeza de que los archivistas no son agentes imparciales sino, inevitablemente, sujetos con su historia, formación y subjetividad (y que esto no debe ser visto como algo negativo, sino todo lo contrario), es precisamente desde la asunción de dicha verdad que se vuelve inteligible la apuesta política del $\mathrm{CeDInCl}$ de conformar un equipo de trabajo con profesionales que vienen de disciplinas diferentes, con formaciones dobles (licenciados en Letras que trabajan como archivistas, archivistas diplomados que son también licenciados en Historia, doctorandos en Historia que trabajan como bibliotecarios, bibliotecarios que trabajan como técnicos informáticos, traductores que trabajan como catalogadores, historiadores que hacen curaduría digital, etc., etc.).

Dentro del área de Archivos y Colecciones Particulares, es de destacar la importancia otorgada a la instancia de la descripción, que aparece siempre "datada" (no era lo mismo el acto de describir en 1900 que en el presente) y "firmada", por considerarse que el acto de la firma no sacraliza ni inviste de autoridad sino que pone negro sobre blanco el carácter subjetivo (y por lo mismo: objeto de posible debate) de toda producción sobre los archivos. Al mismo tiempo, es sabido que la descripción constituye una primera mediación entre el acervo y los usuarios. Y que, como tal, está permeada de intereses, puntos ciegos y deseos propios. Al respecto, la firma operaría como un indicador (un signo de alerta) de dicha mediación.

Si de algo podemos jactarnos en tanto trabajadores del CeDInCl es del esfuerzo constante por desnaturalizar y reflexionar sobre las propias prácticas, por actualizar nuestra propia performance para responder a las nuevas demandas de los usuarios y los desa- fíos que plantea la "revolución digital", actitud que tiene en este segundo congreso sobre archivos personales organizado por el Área de Archivos y Colecciones Particulares quizá la expresión más visible. Promediando el segundo día de nuestro encuentro, quisiera decirles - last but not least- que estoy realmente muy contenta del nivel de las intervenciones y del compromiso demostrado por todos los participantes. Y muy agradecida. Gracias por escucharme.

\section{Referencias Bibliográficas}

Artières, Philippe, "Arquivar a própria vida", en Estudos Históricos, vol. 11, $n^{\circ} 21$, Río de Janeiro, 1998, pp. 9-34. Disponible en http://bibliotecadigital.fgv.br/ojs/index.php/reh/article/view/2061

Artières, Philippe, "Archivarse", Actas de las II Jornadas de discusión/ I Congreso Internacional. Los archivos personales: prácticas archivísticas, problemas metodológicos y usos historiográficos, Buenos Aires, CeDInCl, 2018. Disponible en http://cedinci. unsam.edu.ar/pdf/jornadas/Actas-Archivos-Personales.pdf

Burt, E. S. y Janie Vanpée, Reading the Archive. On Texts and Institutions, New Haven, Yale University Press, 1990.

Brothman, Brian, "Orders of Value: Probing the Theoretical Terms of Archival Practice", en Archivaria, $n^{\circ} 32$, Ottawa, Verano 1991, pp. 78-100.

Brown, Richard, "The Value of 'Narrativity' in the Appraisal of Historical Documents: Foundation for a Theory of Archival Hermeneutics", en Archivaria, n 32, Ottawa, Verano 1991, pp. 152-156.

Cook, Terry, "Mind over Matter: Towards a New Theory of Archival Appraisal", en Barbara L. Craig (ed.), The Archival Imagination: Essays in Honour of Hugh A. Taylor, Ottawa, Association of Canadian Archivists, 1992, pp. 38- 70.

Cook, Terry, "Electronic Records, Paper Minds: The Revolution in Information Management and Archives in the Post-Custodial and Post-Modernist Era", en Archives \& Manuscripts, vol. 22, n², Canberra, 1994, pp. 300-329.

Cook, Terry, "Archival Science and Postmodernism: New Formulations for Old Concepts", en Archival Science, vol. 1, n 1, New Haven, 2001, pp. 3-24.

Cook, Terry y Joan M. Schwartz, "Archives, Records and Power: From (Posmodern) Theory to (Archival) Performance", en Archival Science, vol. 2, $n^{\circ}$ 3, New Haven, 2002, pp. 171-185. 
Derrida, Jacques, La Carte Postale de Socrate à Freud et audèla, París, Aubier-Flammarion, 1980.

Derrida, Jacques, Espectros de Marx. El estado de la deuda, el trabajo del duelo y la nueva internacional, Madrid, Editorial Trotta, 1995.

Derrida, Jacques, Mal de Archivo: una impresión freudiana, Madrid, Editorial Trotta, 1997.

Fukuyama, Francis, El fin de la historia y el último hombre, Barcelona, Planeta de Agostini, [1992] 1994.

Habermas, Jürgen, "La modernidad: un proyecto inacabado", Ensayos políticos, Península, Barcelona, [1981] 1988, pp. 19-36.

Huyssen, Andreas, "Guía del posmodernismo", en Punto de Vista, $n^{\circ} 29$, Buenos Aires, abril-julio de 1987, Separata.

Jameson, Fredric, Posmodernism, Or, the Cultural Logic of Late Capitalism, Durham, North Carolina, Duke University Press, 1991.

Ketelaar, Eric, "Being Digital in People's Archives", en Archives \& Manuscripts, vol. 31, $n^{\circ} 2$, Canberra, noviembre de 2003, pp. 8-22.

Lyotard, Jean-François, La condición posmoderna, Madrid, Ediciones Cátedra, [1979] 2004.

MacNeil, Heather "Picking Our Text: The Archival Description, Authenticity and the Archivist as Editor", en The American Archivist, vol. $68, n^{\circ} 2$, invierno 2005 , pp. 264-278.

Velloso de Oliveira, Lucia Maria, Descrição e pesquisa: Reflexões em torno dos arquivos pessoais, Río de Janeiro, Mobile, 2012.

Yerushalmi, Yosef, Freud's Moses. Judaism Terminable and Interminable, New Haven, Yale University Press, 1991.

\section{Resumen}

La presente comunicación versa alrededor del llamado "giro posmoderno" en la archivología, a partir del impacto producido por una serie de textos, entre los que se cuentan no sólo Mal de Archivo de Jacques Derrida sino también otros, firmados por archivistas como Eric KeteLaar, Terry Cook y Lucia María Velloso de Oliveira, a lo que se sumó dos factores fundamentales: la "revolución informática" y las nuevas demandas y necesidades de la sociedad civil frente al archivo en tanto institución, y, por ende, los nuevos desafíos que se les presentan a los profesionales que trabajan allí. Respecto a esto último, se esboza un estudio de caso: el trabajo que se viene desarrollando en el "Área de Archivos y Colecciones Particulares" del Centro de Documentación e Investigación de la Cultura de Izquierdas (CeDlnCl).

Palabras clave: archivos - "giro posmoderno" - archivología

\section{Abstract:}

\section{The postmodern turn in archivology}

The present work revolves around the so-called "Postmodern Turn" in archival science beginning with the impact of a series of texts, among those not only Archive Fever by Jacques Derrida, but also others authored by archivists such as Eric Ketelaar, Terry Cook and Lucia María Velloso de Oliveira, adding to two crucial factors: the computational revolution and the new demands and needs of civil society regarding the archive as institution, and therefore, the new challenges facing the professionals who work there. With regard to the latter, a case-study is here outlined: the work which which has been carried out in the "Área de Archivos y Colecciones Particulares" of Centro de Documentación de Investigación de la Cultura de Izquierdas (CeDlnCl).

Key words: archives — "Postmodern Turn" — archival science.

Recibido el 03/07/2019 Aceptado el 28/08/2019

Artículo evaluado por pares. 


\section{FEDERACION UNIVERSITARIA}

$\overline{7} \cdot \overline{7} \cdot 5$

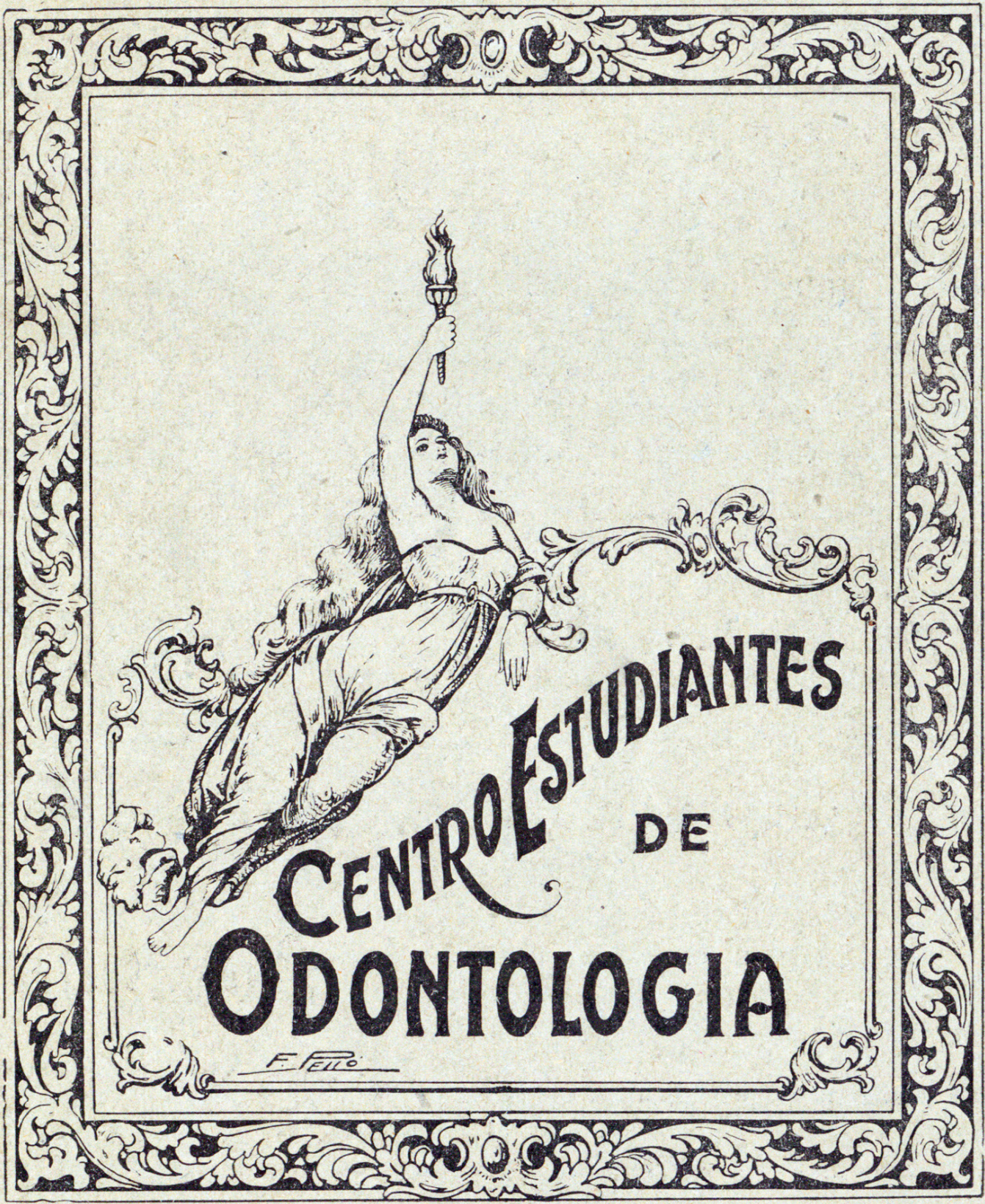

$\mathbb{R}(0) \mathbb{A} \mathbb{R} \mathbb{0}$ 